\title{
Transfemoral transcatheter valve-in-valve-in-valve replacement
}

Stephane Leung Wai Sang, MD, MSc, ${ }^{a}$ Jay Giri, MD, MPH, ${ }^{b}$ and Prashanth Vallabhajosyula, MD, $\mathrm{MS}^{\mathrm{a}}$

\footnotetext{
From the Divisions of a Cardiovascular Surgery and ${ }^{\mathrm{b} C}$ ardiovascular Medicine, Perelman School of Medicine, University of Pennsylvania, Philadelphia, Pa.

Disclosures: Authors have nothing to disclose with regard to commercial support.

Received for publication Dec 16, 2015; revisions received Feb 11, 2016; accepted for publication March 14, 2016; available ahead of print May 11, 2016.

Address for reprints: Prashanth Vallabhajosyula, MD, MS, Division of Cardiovascular Surgery, Hospital of the

University of Pennsylvania, 3400 Spruce St, 6 Silverstein, Philadelphia, PA 19104 (E-mail: prashant. vallabhajosyula@uphs.upenn.edu).

J Thorac Cardiovasc Surg 2016;152:622-3

$0022-5223 / \$ 36.00$

Copyright (C) 2016 Published by Elsevier Inc. on behalf of The American Association for Thoracic Surgery http://dx.doi.org/10.1016/j.jtcvs.2016.03.047
}

Transcatheter valve-in-valve (ViV) implantation for degenerated bioprosthetic aortic valves is feasible with acceptable outcomes. ${ }^{1}$ The transcatheter valve-in-valve-in-valve operation has not been previously reported.

A 64-year-old man with known severe prosthetic aortic stenosis (AS) was admitted for recurrent decompensated heart failure. His past surgical history included open aortic valve replacement for severe AS in 2006 with a $23-\mathrm{mm}$ Perimount Edwards bioprosthesis, followed by a transcatheter ViV implantation with a 23-mm Sapien XT (Edwards Lifesciences, Irvine, Calif) in 2012 for severe prosthetic

\begin{tabular}{|c|c|}
\hline $\begin{array}{l}\text { TICM } \\
\text { VIDEO } \\
\text { CLII }\end{array}$ & Video clip is available online. \\
\hline
\end{tabular}

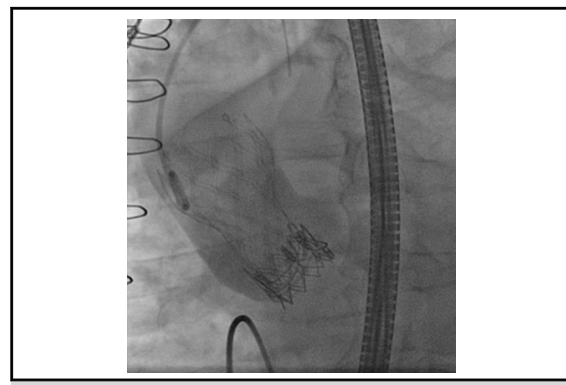

Self-expandible transcatheter valve is placed superiorly in the valvular complex.

Central Message
Transcatheter valve-in-valve-in-valve (ViV)
operation has not been previously reported.
We present the first case of a ViV implantation
for degenerated bioprosthetic aortic valves with
good outcome.

See Editorial Commentary page 624.
AS (peak/mean gradients 121/82.5 mm Hg, and aortic valve area of $\left.0.66 \mathrm{~cm}^{2}\right)$. Present echocardiogram confirmed restenosis (peak/mean gradients, $105 / 65 \mathrm{~mm} \mathrm{Hg}$ ), with preserved left ventricular function. The patient was deemed to be high risk for open surgery, both in 2012 and currently,
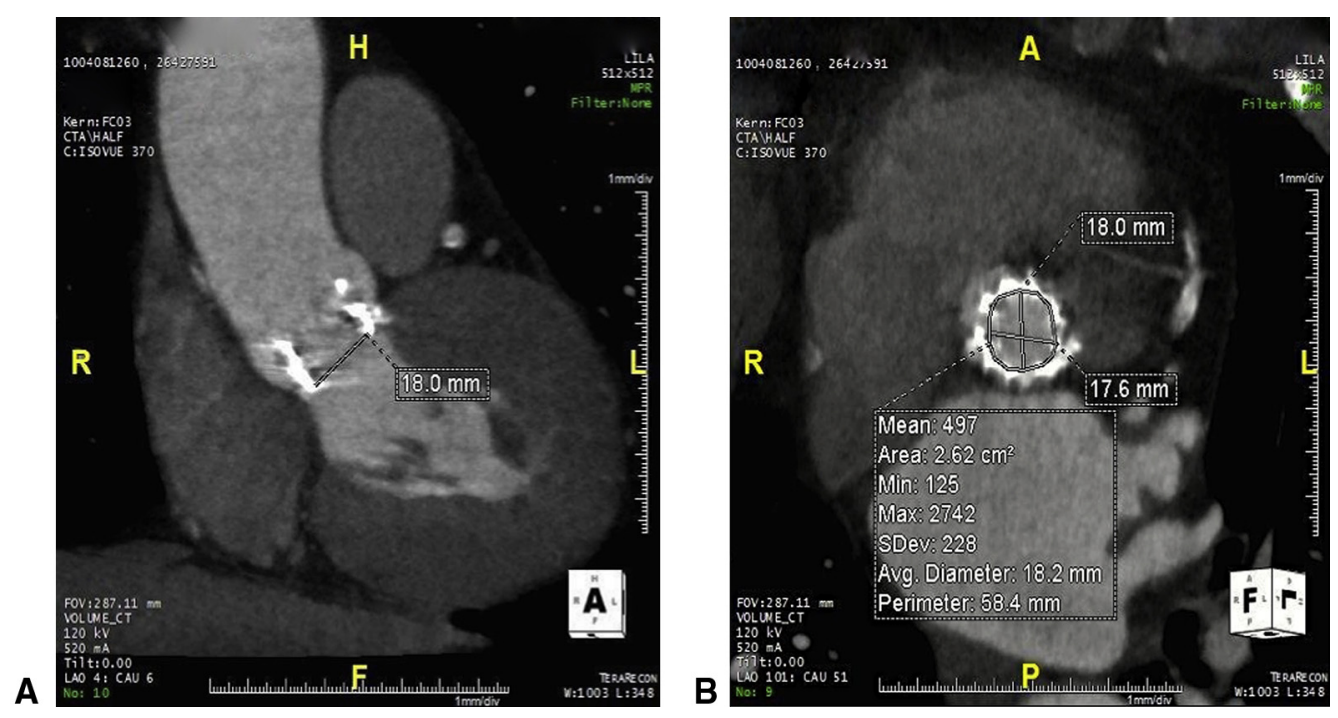

FIGURE 1. Computed tomographic angiogram of the aortic root. A, Long-axis view of the aortic root with 18-mm diameter. B, Short-axis view of the aortic valve illustrating the measured diameter and perimeter. 
A
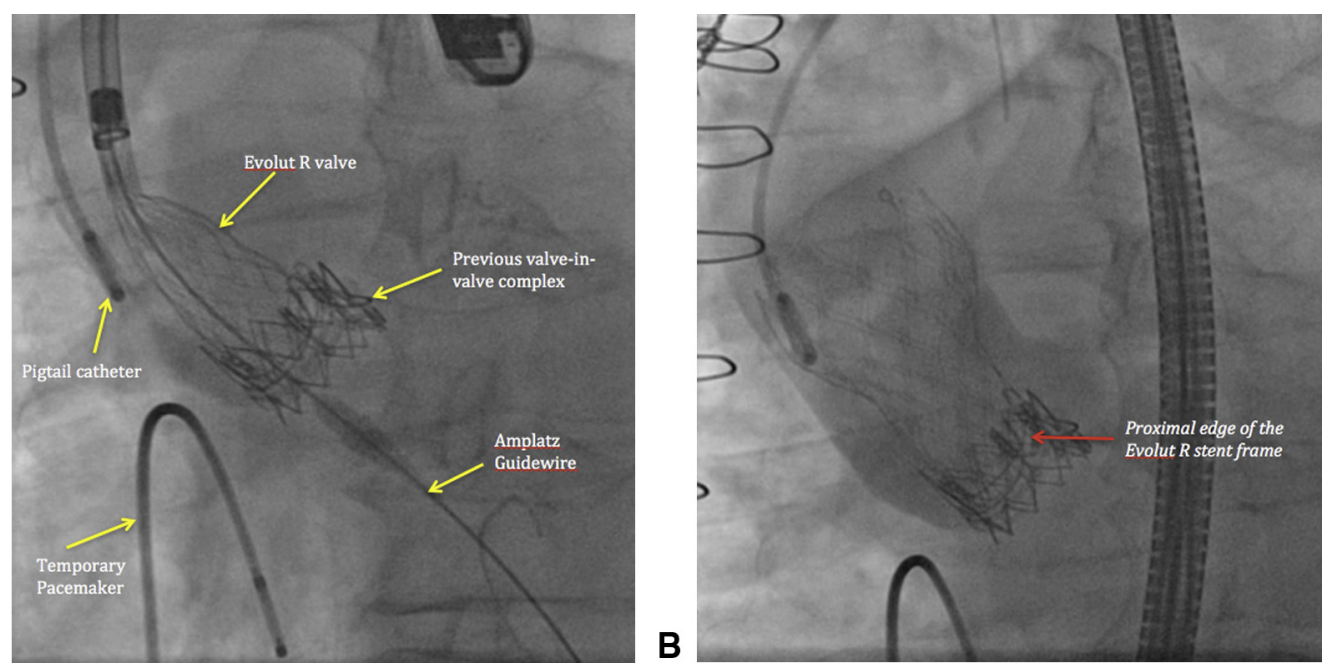

FIGURE 2. Aortogram during valve deployment. A, The transcatheter heart valve is shown in position within the prosthetic valvular complex before complete deployment. B, Final position of the valve after complete deployment, illustrating no valvular or paravalvular leak. Red arrow demonstrates the high positioning of the self-expandable valve.

due to advanced biopsy-proven idiopathic liver cirrhosis (Child Turcotte Pugh Class B) and, therefore, was evaluated for transcatheter intervention.

By computed tomographic angiogram, the aortic annular perimeter measured $58.4 \mathrm{~mm}$, with an average diameter of $18.2 \mathrm{~mm}$ (Figure 1). These measurements dictated use of a

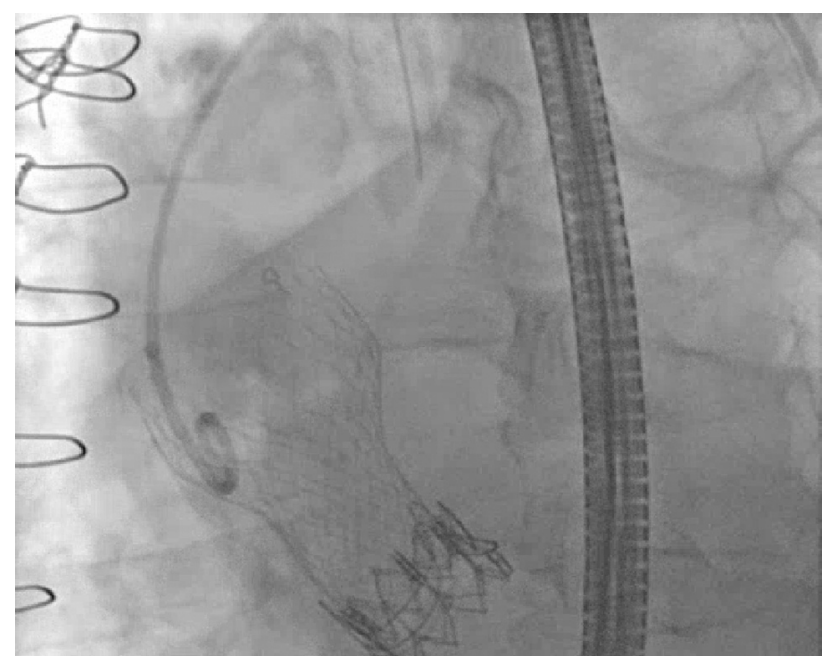

VIDEO 1. Final position of the valve after complete deployment, illustrating no valvular or paravalvular leak. Video available at http:// www.jtcvsonline.org. 23-mm Evolut R (Medtronic, Inc, Minneapolis, Minn) transcatheter heart valve (THV). This valve was chosen primarily due to its supra-annular positioning that was postulated to provide a larger effective bioprosthetic area in the current setting, after consideration also was given to a balloon-expandable 20-mm Sapien XT.

The THV was successfully deployed in a position significantly superior to the prior prosthetic valvular complex, relying on the previous stent frames to provide stability for the most proximal portion of the new stent frame (Figure 2, A). Experimental data support that supravalvular implantation of THV relieves stenosis in a small bioprosthesis. ${ }^{2}$ Postdeployment aortogram showed no residual paravalvular or valvular leak (Figure 2, $B$, and Video 1). Immediate postprocedure transesophageal echocardiography revealed a $50 \%$ reduction in the aortic mean gradient from $62 \mathrm{~mm} \mathrm{Hg}$ to $31 \mathrm{~mm} \mathrm{Hg}$. Follow-up 30-day transthoracic echocardiography revealed a peak/mean gradient of $31 / 21 \mathrm{~mm} \mathrm{Hg}$.

\section{References}

1. Dvir D, Webb JG, Bleiziffer S, Pasic M, Waksman R, Kodali S, et al. Transcatheter aortic valve implantation in failed bioprosthetic surgical valves. JAMA. 2014;312: 162-70.

2. Azadani AN, Jaussaud N, Matthews PB, Ge L, Guy TS, Chuter TA, et al. Valve-invalve implantation using a novel supravalvular transcatheter aortic valve: proof of concept. Ann Thorac Surg. 2009;88:1864-9. 